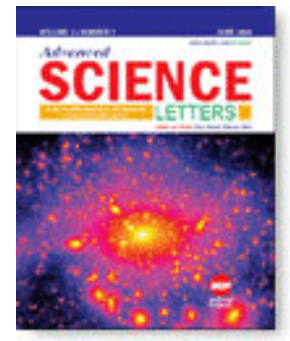

\title{
Post Disaster Management (PDM) in Malaysia: Issues and Challenges
}

Authors: Khuzzan, Sharifah Mazlina Syed; Mohyin, Nur Affah; Izuddin, Sarah

Source: Advanced Science Letters, Volume 23, Number 7, July 2017, pp. 6390-6393(4)

Publisher: American Scientific Publishers

DOI: https://doi.org/10.1166/asl.2017.9276

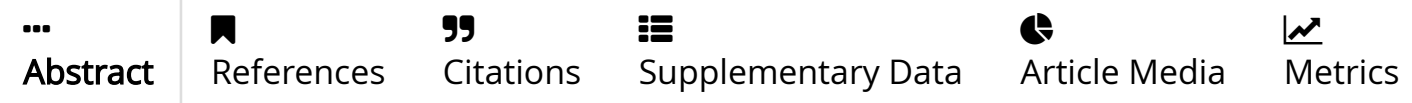

In Malaysia, Kelantan has been well known to experience the flood disaster almost every year. Flood has been considered as a very common disaster in Kelantan, especially during the end of the year. However, the flood in December 2014 has been considered as one of the biggest which had caused massive destruction in many areas in Kelantan especially in Kuala Krai; leading to the destruction of livelihood of local communities. Due to this, it has been considered that it is important to identify the recovery activities and strategies in order to reduce the impact of flood disaster to the life and property of the communities. Hence, the Post-Disaster Management (PDM) is implemented to ensure that any coming disaster that may occur, can be managed effectively. However, literature search has shown that there have been low responses and lack of effectiveness in the recovery activities of flood disaster. Therefore, this paper describes the issues and challenges faced during the PDM activities in Malaysia. In addition, this paper discusses the recommendations made in order to minimise the issues faced in the current practice of the PDM in Malaysia. This study had conducted semistructured interviews involving eight (8) respondents who were directly involved in the management of postflood disaster in Kuala Krai, Kelantan in the year 2014. The findings from the interview conducted has shown that majority of the respondents were in the agreement that the main issues arising from the PDM in Malaysia are: no specific evacuee sleeping areas, as well as lack of immediate supplies of essential needs to the victims. Furthermore, the respondents felt that the government needs to take into consideration several steps to overcome the main issues and challenges such as integration of immediate rescue and relief responses, develop the readiness to sustain the number of emergency, redevelop the drainage systems, as well as to create awareness within the community in order to help the victims' spiritual needs when faced with disaster.

Keywords: Disaster; Disaster Management; Flood; Malaysia; Post-Disaster Management

Document Type: Research Article 
Affiliations: Kulliyyah of Architecture and Environmental Design (KAED), International Islamic University Malaysia, Kuala Lumpur, Malaysia

Publication date: July 1, 2017

More about this publication? 